\title{
BMJ Open Continuity of care: evaluating a multidisciplinary care model for people with early CKD via a nationwide population-based longitudinal study
}

\author{
Yin-Cheng Chen, ${ }^{1}$ Shuen-Fu Weng, ${ }^{2,3}$ Yu-Juei Hsu, ${ }^{4}$ Chung-Jen Wei, ${ }^{5}$ \\ Chiung-hsuan Chiu (i) ${ }^{6}$
}

To cite: Chen Y-C, Weng SF, Hsu Y-J, et al. Continuity of care: evaluating a multidisciplinary care model for people with early CKD via a nationwide population-based longitudinal study. BMJ Open 2020;10:e041149. doi:10.1136/ bmjopen-2020-041149

- Prepublication history for this paper is available online. To view these files, please visit the journal online (http://dx.doi. org/10.1136/bmjopen-2020041149).

Y-CC and S-FW contributed equally.

Received 03 June 2020 Revised 03 December 2020 Accepted 08 December 2020

Check for updates

(C) Author(s) (or their employer(s)) 2020. Re-use permitted under CC BY-NC. No commercial re-use. See rights and permissions. Published by BMJ.

For numbered affiliations see end of article.

Correspondence to Dr Chiung-hsuan Chiu; meg_chiu@tmu.edu.tw

\section{ABSTRACT}

Objectives To control and prevent the burdens associated with chronic kidney disease (CKD), Taiwan's National Health Insurance Administration (NHIA) launched the 'early-CKD programme' in 2011 to extend care and education to patients with CKD. This study aims to evaluate the effectiveness of the early-CKD programme in terms of continuity of care (COC).

Design and participants This study used secondary data from 2010 to 2014 provided by the NHIA to identify 86581 participants each for the intervention and control groups. Patients with CKD who participated in the earlyCKD programme between 2011 and 2013 were defined as the intervention group. For the control group, propensity score matching was used to select patients with CKD who did not participate in the programme, but were seen by the same group of physicians.

Intervention A multidisciplinary care model for patients with early CKD launched in 2011.

Primary outcome measures Outcome variables included the continuity of care index $(\mathrm{COCl})$, which measures a physician's COC; number of essential examinations; and resource utilisation. To better identify the difference between groups, we separated $\mathrm{COCl}$ into two groups based on mean: high (above mean) and low (below mean). A generalised estimating equation model was used to examine the effects of the early-CKD programme.

Results The programme significantly increased the number of essential examinations/tests administered to patients $(\beta=0.61, p<0.001)$ and improved $\mathrm{COCl}$ between physicians and patients $(0 R=4.18, p<0.001)$. Medical expenses $(\beta=1.03, p<0.001)$ and medication expenses $(\beta=0.23, p<0.001)$ significantly increased after the programme was implemented, but patients' kidneyrelated hospitalisations and emergency department visits decreased $(\beta=-0.13, p<0.001)$.

Conclusion From the $\mathrm{COC}$ viewpoint, the programme in Taiwan showed a positive effect on $\mathrm{COCl}$, number of essential examinations and resource utilisation.

\section{BACKGROUND}

In most developed countries, $10 \%-13 \%$ of the general population have chronic kidney disease (CKD). Although only $0.03 \%-0.23 \%$ have end-stage renal disease (ESRD) and
Strengths and limitations of this study

The population-based data set provides a higher level of accuracy than a smaller data set can provide.

- This is only an initial examination of continuity of care for an early-CKD programme in Taiwan.

- The use of claims data rather than clinical data might obscure the true efficacy of the programme.

have received renal replacement therapy, $2 \%-7 \%$ of the annual healthcare budget, or 30-100 times the average individual's healthcare expenditure, is used for this population. ${ }^{1-3}$ Most ESRD cases develop from progressive CKD, which is becoming a tremendous economic burden. CKD is also associated with high premature mortality and disability rates ${ }^{4}$ and an 8 -fold to 10 -fold increase in cardiovascular mortality. ${ }^{56} \mathrm{CKD}$ is also a risk multiplier in patients with diabetes and hypertension. CKD is a neglected noncommunicable disease and is becoming a global public health issue. ${ }^{7}$

Some countries have started prevention programmes to address this burden. ${ }^{389}$ Multidisciplinary care (MDC) models that incorporate professionals from various aspects of the healthcare system have been widely adopted. ${ }^{10-13}$ Some have even provided financial incentives (pay-for-performance $(\mathrm{P} 4 \mathrm{P}))$ to healthcare providers who participate in such programmes. ${ }^{14}$ Studies have shown that these programmes are effective in containing medical expenditures for predialysis patients, reducing hospitalisation and better controlling CKD complications. ${ }^{15-17}$ However, incidence and mortality rates were hardly improved, ${ }^{18-21}$ likely because it was too late to start prevention at early-CKD stages.

In 2003, Taiwan's National Health Insurance Administration (NHIA) proposed multidisciplinary educational and care 
projects targeting patients with pre-ESRD, and in 2006, it launched a programme to promote early and active CKD intervention. The projects encourage medical institutions to build multidisciplinary renal teams led by nephrologists that include nurses, dieticians, case managers and pharmacists to set up professional CKD training courses and health management system platforms, in addition to review systems for the platforms. They also screened high-risk groups, starting from the relatives of dialysis patients, and established screening tools in local communities. The programmes primarily aimed to slow the progression of CKD and reduce ESRD incidence. $^{22}$ In 2018, 191 medical institutions provided kidney health promotion services. ${ }^{23}$

To increase patients' knowledge of kidney disease and improve healthcare management, the project was expanded to a nationwide pre-ESRD P4P programme moderated by the NHIA. Initial reports have shown that the programme may be decreasing dialysis and mortality rates, and is saving on CKD-related costs. ${ }^{15} 162425$ Nevertheless, the incidence of ESRD has remained unchanged.

To help address Taiwan's rapidly ageing population and other increasingly common risk factors, the NHIA in 2011 launched a programme for patients with early CKD (stages 1-3a) in high-risk populations, such as the elderly or those with diabetes mellitus, hypertension or a family history of CKD. The programme was designed to achieve three main goals: to provide patient-centred care, to ensure follow-up care is provided by the same physicians, and to pay providers according to a P4P scheme. ${ }^{26}$ Physicians other than nephrologists, cardiologists and endocrinologists joined the care model to encourage patients with early CKD to enroll in the programme. The ultimate aim is to enhance the efficiency and effectiveness of disease management through medical care and further education. However, there were some issues with the programme that need to be highlighted: (1) patients with early CKD are relatively young and healthy, so they are more reluctant to change their diet and behaviours, and (2) patients usually visit primary and general healthcare providers, so general practitioners (GPs) should be able to provide kidney care. For the first issue, the MDC model could help by providing wider and deeper contact with patients. As part of the $\mathrm{P} 4 \mathrm{P}$ programme that rapidly expanded nationwide, GPs and other professionals are asked to take a 6 -hour kidney care training course and retain at least $20 \%$ of new enrollees each year. They are also subject to periodic reviews. The 6-hour training course for GPs and other professionals covers basic care protocol for patients with CKD, including the definition and stages of CKD, medicinal regimens, care protocol for patients with comorbidities and healthy lifestyle. ${ }^{26}$ Education for patients with CKD is required to include an introduction to the disease (symptoms and how to interpret test results), instructions on maintaining a healthy lifestyle, and administering medication, diet, the importance of returning for follow-ups and how to slow the progress of $\mathrm{CKD}^{26}$
Continuity of care (COC) is a core element of primary care and has been linked to adherence. ${ }^{27}{ }^{28}$ For patients with chronic diseases, a long-term physicianpatient relationship can improve communication and enhance understanding, leading to effective chronic disease management. ${ }^{29-31} \mathrm{COC}$ is also helpful for health providers to understand patients' medication adherence and retention of disease knowledge. ${ }^{3233}$ The continuity of care index (COCI) has been used to evaluate the effectiveness of prevention programmes for diseases such as diabetes mellitus, hypertension and chronic obstructive pulmonary disease, but not yet for CKD. ${ }^{34-36}$ As it takes a long time for early CKD to develop into ESRD, it is difficult to evaluate the effectiveness of an early-CKD prevention programme based solely on the incidence of ESRD. Therefore, this study aims to understand the association between COCI and resource utilisation before and after an early-CKD programme intervention.

\section{METHODS}

\section{Data sources}

This study used NHIA claims data from 2010 to 2014 of patients with CKD who enrolled in an early-CKD intervention programme. Enrollees were identified by their payment code: P4301C, P4302C and P4303C. ${ }^{37}$ All personal identification was removed, and the authors accessed the data under strict supervision of the NHIA. To be included in the study, patients with CKD had to be $>20$ years old and should have made at least three outpatient visits or been admitted to hospitals more than once for CKD-related diseases. Patients who had received dialysis or a kidney transplant were excluded. The International Classification of Diseases, Ninth Revision, Clinical Modification of CKD was defined by the US Renal Data System and the NHIA of the Taiwanese Ministry of Health and Welfare, including 016.0, 095.4, 189.0, 189.9, 223.0, 236.91, 250.4, 271.4, 274.1, 283.11, 403.x1, 404.x2, 404. x3, 440.1, 442.1, 447.3, 572.4, 581-588, 591, 642.1, 646.2, $753.12-753.19,753.2$ or $794.4 .^{38} 39$

\section{Study subjects}

This study used an intervention and a control group. The intervention group included eligible subjects who participated in the early-CKD programme any time from 2011 to 2013. Their claims data were collected the year before the index year and 1 year after the index year. The study excluded subjects who participated in the preESRD programme before they enrolled in the early-CKD programme. The index date was defined as the first day an eligible patient enrolled in the early-CKD programme between 1 January 2011 and 31 December, 2013. The timeline is plotted in figure 1 .

The control group included patients with CKD cared for by the physicians who joined the care model, but who did not enrol in the early-CKD programme during the study period. Propensity score matching was used to match subjects in both groups in terms of gender, age, year of 


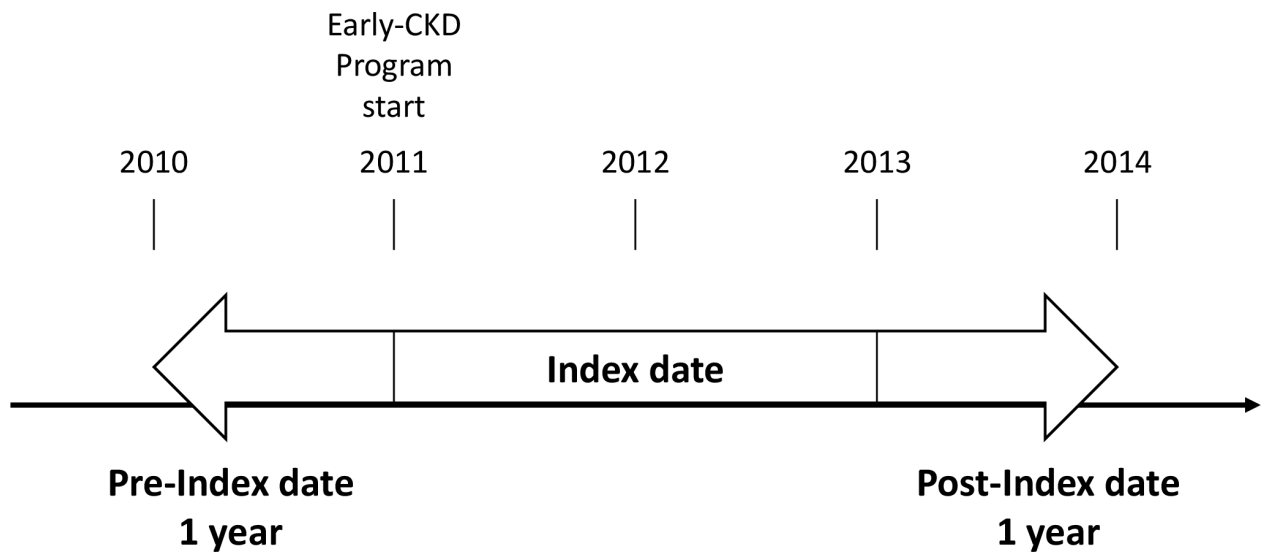

Figure 1 Participant study period. CKD, chronic kidney disease.

diagnosis, comorbidity (such as hypertension, diabetes and cardiovascular diseases), Dartmouth-Manitoba's Charlson Comorbidity Index (D-M's CCI) ${ }^{40}$ accreditation level and location of hospitals that participants visited most frequently. Each group had 86581 eligible participants to assure matched distribution (figure 2).

\section{Study variables}

\section{Outcome variables}

Five outcome variables were included: COCI, number of essential examinations/tests and resource utilisation (number of admissions to hospitals or emergency department (ED) visits due to kidney-related illness, medical expenditures and medication expenditures). The COCI score measured the physicians' COC from 0 to 1. The higher the score, the better the COC provided to patients, meaning that patients regularly visited the same

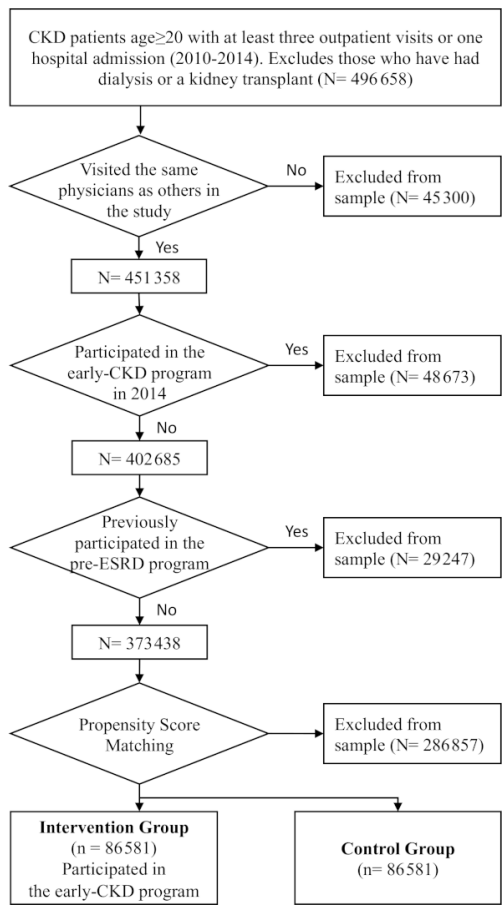

Figure 2 Study participant screening process. CKD, chronic kidney disease; ESRD, end-stage renal disease. physicians. The COCI formula is as follows, where $N$ is the total number of outpatient CKD care visits, $n_{i}$ is the number of outpatient CKD care visits to a physician (i) and $M$ is the total number of physicians ${ }^{32}$ :

$$
\frac{\sum_{i=1}^{M} n_{i}^{2}-N}{N(N-1)}
$$

To better identify the difference between groups, we used means of COCI to transform COCI into two groups: high (above mean) and low (below mean).

Essential examinations/tests included regular urine protein-to-creatinine ratio or urine albumin-to-creatinine ratio tests during outpatient visits. The number of admissions to hospitals or ED visits due to kidney-related illness, medical expenditures (outpatient and inpatient) and medication expenditures were measured as resource utilisation indicators.

\section{Independent variables and covariates}

This study included demographic variables, D-M's CCI index, comorbidity (including diabetes, hypertension and cardiovascular disease), hospital accreditation level (medical centre, regional hospital, district hospital, community clinic and unclear) and hospital location (Taipei area, northern, central, southern, Kaohsiung/ Pingtung, eastern and unclear). Interaction terms of the intervention/control group and time were also examined.

The D-M's CCI scores 17 categories of disease, including myocardial infarction; congestive heart failure; peripheral vascular disease; cerebrovascular disease; dementia; chronic pulmonary disease; connective tissue disease; ulcer disease; mild liver disease; diabetes; diabetes with end-organ damage; hemiplegia; moderate or severe renal disease; any tumour, leukaemia, lymphoma; moderate or severe liver disease; metastatic solid tumour; and AIDS on a scale starting from $0($ no $=0$, mild $=1$, moderate $=2$, severe $=\geq 3) .{ }^{41}$ For this study, 16 of the categoriesexcluding moderate or severe renal disease-need to be considered. $^{42}$

\section{Statistical analysis}

Data were analysed by SAS V.9.4. Descriptive statistics were reported. Standardised mean difference (SMD) analysis was 
Table 1 Characteristics of participants in the prematched and postmatched samples

\begin{tabular}{|c|c|c|c|c|c|c|c|c|c|c|}
\hline \multirow{3}{*}{$\begin{array}{l}\text { Group } \\
\text { Independents }\end{array}$} & \multicolumn{5}{|c|}{ Prematched sample } & \multicolumn{5}{|c|}{ Postmatched sample } \\
\hline & \multicolumn{2}{|c|}{$\begin{array}{l}\text { Intervention } \\
(\mathrm{n}=92522)\end{array}$} & \multicolumn{2}{|c|}{$\begin{array}{l}\text { Control } \\
(n=280916)\end{array}$} & \multirow[b]{2}{*}{ SMD } & \multicolumn{2}{|c|}{$\begin{array}{l}\text { Intervention } \\
(\mathrm{n}=86581)\end{array}$} & \multicolumn{2}{|c|}{$\begin{array}{l}\text { Control } \\
(n=86581)\end{array}$} & \multirow[b]{2}{*}{ SMD } \\
\hline & $\mathbf{n}$ & $\%$ & $\mathbf{n}$ & $\%$ & & $\mathbf{n}$ & $\%$ & $\mathbf{n}$ & $\%$ & \\
\hline \multicolumn{11}{|l|}{ Gender } \\
\hline Male & 47401 & 51.2 & 153783 & 54.7 & 0.07 & 44821 & 51.8 & 44821 & 51.8 & 0.00 \\
\hline Female & 45121 & 48.8 & 127133 & 45.3 & & 41760 & 48.2 & 41760 & 48.2 & \\
\hline \multicolumn{11}{|l|}{ Age (years) } \\
\hline$\leq 55$ & 22421 & 24.2 & 85743 & 30.5 & 0.14 & 21087 & 24.4 & 21087 & 24.4 & 0.00 \\
\hline $56-65$ & 28021 & 30.3 & 64894 & 23.1 & 0.16 & 25686 & 29.7 & 25686 & 29.7 & 0.00 \\
\hline $66-75$ & 26189 & 28.3 & 61503 & 21.9 & 0.14 & 24222 & 28.0 & 24222 & 28.0 & 0.00 \\
\hline $76+$ & 15891 & 17.2 & 68776 & 24.5 & 0.17 & 15586 & 18.0 & 15586 & 18.0 & 0.00 \\
\hline \multicolumn{11}{|c|}{ First year in early-CKD programme } \\
\hline 2011 & 21542 & 23.3 & 71104 & 25.3 & 0.04 & 19269 & 22.3 & 19269 & 22.3 & 0.00 \\
\hline 2012 & 28908 & 31.2 & 88203 & 31.4 & 0.00 & 27561 & 31.8 & 27561 & 31.8 & 0.00 \\
\hline 2013 & 42072 & 45.5 & 121609 & 43.3 & 0.04 & 39751 & 45.9 & 39751 & 45.9 & 0.00 \\
\hline \multicolumn{11}{|l|}{$\mathrm{CCl}$ index score } \\
\hline 0 & 16836 & 18.2 & 96468 & 34.3 & 0.37 & 16711 & 19.3 & 16928 & 19.6 & 0.00 \\
\hline $1-2$ & 46667 & 50.4 & 103518 & 36.9 & 0.27 & 42428 & 49.0 & 41919 & 48.4 & 0.01 \\
\hline$\geq 3$ & 29019 & 31.4 & 80930 & 28.8 & 0.05 & 27442 & 31.7 & 27734 & 32.0 & 0.00 \\
\hline \multicolumn{11}{|l|}{ Comorbidity } \\
\hline Diabetes & 58357 & 63.1 & 113852 & 40.5 & 0.46 & 52642 & 60.8 & 52240 & 60.3 & 0.01 \\
\hline Hypertension & 64396 & 69.6 & 152667 & 54.3 & 0.32 & 59414 & 68.6 & 60219 & 69.6 & 0.02 \\
\hline Cardiovascular diseases & 25137 & 27.2 & 74224 & 26.4 & 0.01 & 23817 & 27.5 & 24062 & 27.8 & 0.00 \\
\hline \multicolumn{11}{|l|}{ Hospital accreditation level } \\
\hline Medical centre & 14371 & 15.5 & 67815 & 24.1 & 0.21 & 12067 & 13.9 & 12067 & 13.9 & 0.00 \\
\hline Regional hospital & 25014 & 27.0 & 100071 & 35.6 & 0.18 & 23778 & 27.5 & 23778 & 27.5 & 0.00 \\
\hline District hospital & 12944 & 14.0 & 4473 & 15.9 & 0.05 & 12507 & 14.4 & 12507 & 14.4 & 0.00 \\
\hline Community clinic/unclear & 40193 & 43.4 & 68292 & 24.3 & 0.41 & 38229 & 44.2 & 38229 & 44.2 & 0.00 \\
\hline \multicolumn{11}{|l|}{ Hospital location } \\
\hline Taipei region & 3918 & 4.2 & 70485 & 25.1 & 0.61 & 3915 & 4.5 & 3915 & 4.5 & 0.00 \\
\hline Northern region & 5636 & 6.1 & 25972 & 9.2 & 0.11 & 5601 & 6.5 & 5601 & 6.5 & 0.00 \\
\hline Central region & 19450 & 21.0 & 44338 & 15.8 & 0.13 & 17101 & 19.8 & 17101 & 19.8 & 0.00 \\
\hline Southern region & 8600 & 9.3 & 33427 & 11.9 & 0.08 & 7876 & 9.1 & 7876 & 9.1 & 0.00 \\
\hline Kaohsiung/Pingtung region & 14105 & 15.2 & 32850 & 11.7 & 0.10 & 13269 & 15.3 & 13269 & 15.3 & 0.00 \\
\hline Eastern region & 625 & 0.7 & 5809 & 2.1 & 0.11 & 593 & 0.7 & 593 & 0.7 & 0.00 \\
\hline Unclear & 40188 & 43.4 & 68035 & 24.2 & 0.41 & 38226 & 44.2 & 38226 & 44.2 & 0.00 \\
\hline
\end{tabular}

Standardised mean difference (SMD)=difference in mean outcome between groups/SD of outcome among participants; SMD >0.1 means there is a significant difference.

$\mathrm{CCl}$, Charlson Comorbidity Index; CKD, chronic kidney disease.

used to compare outcomes before and after the implementation of the early-CKD programme between the intervention and control groups. Regression, generalised estimating equation (GEE) models, adjusted demographic variables (such as gender, age and comorbidity) and hospital characteristics (such as accreditation level and location) were used to examine the relationship between independent and dependent variables. Moreover, the COCI GEE model was analysed based on binomial distribution and logit link, whereas the models on other outcome variables were based on Poisson distribution.

Patient and public involvement

Patients and the public were not involved in this study. 
Table 2 Distribution of dependent variables by period of participation in the early-CKD programme

\begin{tabular}{|c|c|c|c|c|}
\hline \multirow{2}{*}{$\begin{array}{l}\text { Period } \\
\text { Dependents }\end{array}$} & \multicolumn{2}{|c|}{ Pre-early CKD 1 year } & \multicolumn{2}{|c|}{ Post-early CKD 1 year } \\
\hline & Mean & SD & Mean & SD \\
\hline \multicolumn{5}{|c|}{ Number of essential examinations/tests (mean, SD) } \\
\hline Intervention group & 1.12 & 1.16 & 2.76 & 1.42 \\
\hline Control group & 0.50 & 0.96 & 0.67 & 1.13 \\
\hline \multicolumn{5}{|l|}{$\mathrm{COCl}$ (mean, SD) } \\
\hline Intervention group & 0.24 & 0.40 & 0.81 & 0.28 \\
\hline Control group & 0.37 & 0.44 & 0.44 & 0.45 \\
\hline \multicolumn{5}{|c|}{ Kidney-related inpatient or ED visits (N, \%) } \\
\hline Intervention group & 0.04 & 0.24 & 0.04 & 0.27 \\
\hline Control group & 0.12 & 0.51 & 0.16 & 0.63 \\
\hline \multicolumn{5}{|c|}{ Medical expenses* (mean, SD) } \\
\hline Intervention group & 4963 & 20432 & 17491 & 32857 \\
\hline Control group & 12540 & 62657 & 15836 & 69253 \\
\hline \multicolumn{5}{|c|}{ Medicine expenses* (mean, SD) } \\
\hline Intervention group & 5676 & 9209 & 7670 & 11488 \\
\hline Control group & 5260 & 10005 & 5669 & 9789 \\
\hline
\end{tabular}

*Measured in payment points, which fluctuate from month to month. A point is equivalent to 0.9 New Taiwanese Dollars, which is equivalent to US\$0.03. (Retrieved: https://rate.bot.com.tw/xrt?Lang=zh-TW)

$\mathrm{CKD}$, chronic kidney disese; $\mathrm{COCl}$, continuity of care index; ED, emergency department.

\section{RESULTS}

To ensure even distribution after matching, the intervention and control groups were selected based on propensity score (calculated by participants' age, CCI index score, comorbidity, accreditation level and hospital location). Table 1 shows no significant difference between groups in the baseline characteristics of patients between the prematched sample (SMD $>0.1$ ) and after matching $(\mathrm{SMD}<0.1)$. Further analysis was conducted based on the postmatched samples.

Descriptive statistics of the study variables are shown in table 2. The average number of essential examinations/ tests in the intervention group was higher than in the control group in the pre-early CKD programme, which was considered as the baseline year. One year after the early-CKD programme, the average number of essential examinations/tests of the intervention group was higher than in the baseline year. The average COCI for the two groups was similar in the baseline year. One year after the early-CKD programme, the mean COCI for the intervention group increased nearly four times to 0.81 , but that of the control group only increased to 0.44 from the baseline year. The number of hospital admissions or ED visits due to kidney-related diseases were similar in the baseline year $(0.04)$ and 1 year after participating in the programme for the intervention group, but increased from 0.12 to 0.16 1 year after the programme for the control group. Healthcare and medication expenditures for the intervention group were higher than for the control group 1 year after the programme. The number of essential examinations and total medicine expenses were higher in the year before intervention for the intervention group, whereas all other outcome variables (COCI, kidney-related inpatient or ED visits, and medical expenses) were higher in the control group. After intervention, all outcome variables were higher in the intervention group.

Further analysis on the effects of the early-CKD programme was confirmed by the GEE models shown in table 3. The number of essential examinations/tests $(\beta=0.61, p<0.001)$ and medication expenses $(\beta=0.08$, $\mathrm{p}<0.001$ ) increased more for the intervention group between the preintervention year and postintervention year than for the control group. However, hospital admissions $(\beta=-1.18, \mathrm{p}<0.001)$ and healthcare expenses $(\beta=-0.92, p<0.001)$ decreased significantly for the intervention group. Younger patients (age $\leq 55$ years, $\mathrm{OR}=1$; age $>76$ years, $\mathrm{OR}=0.74$ ) were most likely to visit the same physicians.

\section{DISCUSSION}

\section{Major findings}

An examination of early-CKD intervention programme outcome variables shows that the intervention group had a significantly higher number of renal laboratory examinations, healthcare expenses and medication expenses compared with the control group after matching for propensity scores. The number of emergency services provided and hospitalisations were similar before and after the intervention.

The group-and-time interaction effect, or the OR, of COCI was 4.18 , significantly higher in the intervention 
Table 3 Effect of early-CKD programme (GEE model)

\begin{tabular}{|c|c|c|c|c|c|c|c|c|c|c|}
\hline \multirow[b]{2}{*}{$\begin{array}{l}\text { Dependents } \\
\text { Independents (reference) }\end{array}$} & \multicolumn{2}{|c|}{$\begin{array}{l}\text { Number of essential } \\
\text { examinations/tests }\end{array}$} & \multicolumn{2}{|c|}{$\mathrm{COCl}^{*}$} & \multicolumn{2}{|c|}{$\begin{array}{l}\text { Kidney-related } \\
\text { inpatient or ED } \\
\text { visits }\end{array}$} & \multicolumn{2}{|c|}{$\begin{array}{l}\text { Medical } \\
\text { expenses }\end{array}$} & \multicolumn{2}{|c|}{$\begin{array}{l}\text { Medicine } \\
\text { expenses }\end{array}$} \\
\hline & $\beta$ & $\begin{array}{l}P \\
\text { value }\end{array}$ & OR & $\begin{array}{l}P \\
\text { value }\end{array}$ & $\beta$ & $\begin{array}{l}P \\
\text { value }\end{array}$ & $\boldsymbol{\beta}$ & $\begin{array}{l}P \\
\text { value }\end{array}$ & $\beta$ & $\begin{array}{l}P \\
\text { value }\end{array}$ \\
\hline $\begin{array}{l}\text { Intervention group (control } \\
\text { group) }\end{array}$ & 0.81 & $<0.001$ & 0.57 & $<0.001$ & -1.18 & $<0.001$ & -0.92 & $<0.001$ & 0.08 & $<0.001$ \\
\hline \multicolumn{11}{|l|}{ Period (pre-early CKD 1 year) } \\
\hline Post-early CKD 1 year & 0.29 & $<0.001$ & 1.31 & $<0.001$ & 0.27 & $<0.001$ & 0.23 & $<0.001$ & 0.08 & $<0.001$ \\
\hline Interaction group xperiod & 0.61 & $<0.001$ & 4.18 & $<0.001$ & -0.13 & $<0.001$ & 1.03 & $<0.001$ & 0.23 & $<0.001$ \\
\hline Gender (female) & 0.01 & 0.531 & 1.04 & $<0.001$ & 0.02 & 0.254 & 0.08 & $<0.001$ & -0.01 & 0.524 \\
\hline \multicolumn{11}{|l|}{ Age ( $\leq 55$ years) } \\
\hline $56-65$ & -0.03 & $<0.001$ & 0.92 & $<0.001$ & -0.17 & $<0.001$ & -0.12 & $<0.001$ & 0.07 & $<0.001$ \\
\hline $66-75$ & -0.07 & $<0.001$ & 0.85 & $<0.001$ & -0.09 & 0.002 & -0.15 & $<0.001$ & 0.11 & $<0.001$ \\
\hline $76+$ & -0.14 & $<0.001$ & 0.74 & $<0.001$ & 0.27 & $<0.001$ & -0.10 & $<0.001$ & 0.05 & $<0.001$ \\
\hline Hypertension (none) & 0.04 & $<0.001$ & 1.21 & $<0.001$ & 0.20 & $<0.001$ & 0.16 & $<0.001$ & 0.32 & $<0.001$ \\
\hline Diabetes (none) & 0.10 & $<0.001$ & 0.84 & $<0.001$ & -0.29 & $<0.001$ & -0.01 & 0.755 & 0.45 & $<0.001$ \\
\hline Cardiovascular diseases (none) & -0.04 & $<0.001$ & 0.77 & $<0.001$ & 0.37 & $<0.001$ & 0.09 & $<0.001$ & 0.20 & $<0.001$ \\
\hline \multicolumn{11}{|l|}{$\mathrm{CCl}$ index score $(0)$} \\
\hline $1-2$ & 0.10 & $<0.001$ & 1.66 & $<0.001$ & 0.31 & $<0.001$ & 0.40 & $<0.001$ & 0.32 & $<0.001$ \\
\hline$\geq 3$ & 0.21 & $<0.001$ & 3.33 & $<0.001$ & 1.20 & $<0.001$ & 1.00 & $<0.001$ & 0.46 & $<0.001$ \\
\hline \multicolumn{11}{|c|}{ Hospital accreditation level (community clinic) } \\
\hline Medical centre & 0.41 & 0.115 & 1.91 & 0.199 & 0.97 & 0.247 & 1.18 & 0.001 & 0.18 & 0.708 \\
\hline Regional hospital & 0.36 & 0.160 & 1.79 & 0.246 & 0.82 & 0.325 & 0.95 & 0.007 & -0.02 & 0.961 \\
\hline District hospital & 0.32 & 0.207 & 1.63 & 0.332 & 0.63 & 0.450 & 0.86 & 0.015 & -0.40 & 0.404 \\
\hline \multicolumn{11}{|c|}{ Hospital location (Kaohsiung/Pingtung and eastern region) } \\
\hline Taipei and northern region & 0.08 & $<0.001$ & 1.32 & $<0.001$ & 0.07 & 0.014 & 0.01 & 0.938 & 0.31 & $<0.001$ \\
\hline Central and southern region & 0.01 & 0.634 & 1.16 & $<0.001$ & 0.14 & $<0.001$ & 0.05 & 0.012 & 0.16 & $<0.001$ \\
\hline Unclear & 0.12 & 0.643 & 1.63 & 0.333 & -0.17 & 0.836 & 0.15 & 0.676 & 0.56 & 0.248 \\
\hline
\end{tabular}

${ }^{*} \mathrm{COCl}$ is a dichotomous variable and transforms into two groups: high (above mean) and low (below mean).

$\mathrm{CKD}$, chronic kidney disease; $\mathrm{COCl}$, continuity of care index; ED, emergency department; GEE, generalised estimating equation.

group after intervention. This indicates that both group and time were important determinants of COCI and suggests that the intervention could result in increased COCI and closer renal status monitoring.

Early CKD is conventionally managed by conducting renal laboratory examinations. The mean frequency of renal laboratory examinations in the intervention group was 2.76 times per year, which met the goal of at least one examination every 6 months by the early-CKD programme and was significantly more than the 0.67 times per year recorded in the control group. The adequate number of examinations also suggested that the intervention group had a better understanding of their renal status. Many guidelines, such as the Kidney Disease Improvement Global Outcomes, suggest that patients receive CKD-related laboratory tests at least once a year to detect possible deterioration of renal functionality, ${ }^{43}$ but for high-risk CKD groups, such as the elderly or patients with comorbidities, patients are recommended to check more frequently to detect renal deterioration in a timely manner. The early-CKD programme in Taiwan set a guideline to check laboratory data every 6 months. The results also serve as the key performance indicator for the programme. Studies discussing the use of outpatient utilisation services for people with multiple chronic conditions or those under a comprehensive care model have reported the significant effect of such care models. ${ }^{44} 45$

The increased medical expenses indicate more delicate renal care from increased COCI. The early-CKD programme also set many targets for controlling comorbidities, such as blood pressure, haemoglobin A1C, total cholesterol and low-density lipoprotein cholesterol. The increased medication expenses might have been caused by stricter control of the targets. Therefore, the higher expenses in the intervention group might have resulted from the programme, although it should be a necessary secondary prevention cost. Other studies have disagreed, finding that patient care via comprehensive care models 
spent less on healthcare than usual care $^{45}$ or had no difference. ${ }^{46}$ The outcome (use of emergency services and hospitalisation) failed to show any difference, probably because of the short follow-up time in this study.

\section{Care model}

Most current care models incorporate $\mathrm{P} 4 \mathrm{P}$ incentives, multidisciplinary health providers and so on to better manage chronic diseases, ${ }^{47-50}$ all of which improve continuity and quality of care, and emphasise patients' active role in disease management. Taiwan's government has launched an early-CKD programme that incorporates multidisciplinary health providers, provides health education to patients, reduces patients' 'shopping' behaviour and encourages continuous follow-ups. This model integrates multidisciplinary health providers to impose COC. We recommend encouraging patients to understand their illness and adhere to a healthy lifestyle to successfully manage their condition. ${ }^{50}$

\section{Limitations}

There are four major limitations of this study. First, it used claims data 1 year before and 1 year after the intervention, which reported very preliminary progress. A longer follow-up period is recommended for future studies. Second, the data were collated for the purpose of expense claims and are therefore missing some clinical information, such as CKD stage and laboratory data. However, this study used proxy variables to define the control group of patients with early CKD. Third, although we managed to include patients cared for by the same physicians, there were moderating variables (such as demographics, medication adherence, dietary adherence and lifestyle) that also affected health outcomes. There are also a number of reasons why some patients with CKD might not have enrolled in the MDC model, such as failure of physicians to notify patients about the programme, unavailability of dieticians/nurses during patients' visits and patient choice. Fourth, we were not able to generalise how healthcare providers educated their patients, which might have led to possible variance.

\section{Conclusions}

To face the huge burden and critical public health danger posed by CKD, many governments have tried to intervene during the pre-ESRD stage to stop progression to ESRD, but the general results have been unsatisfactory or controversial. Some governments are therefore intervening at an earlier stage. To tackle the problem, in 2011 Taiwan's NHIA launched an early-CKD programme in primary care settings using an MDC model. Participants had a much higher COC and visited health providers more frequently than non-participants. From the viewpoint of COC, the programme has had a positive effect.

\section{Author affiliations}

${ }^{1}$ Division of Nephrology, Department of Internal Medicine, Taipei Hospital, Ministry of Health and Welfare, Taipei, Taiwan
${ }^{2}$ Division of Endocrinology and Metabolism, Department of Internal Medicine, Taipei Medical University Hospital, Taipei, Taiwan

${ }^{3}$ Division of Endocrinology and Metabolism, Department of Internal Medicine, School of Medicine, College of Medicine, Taipei Medical University, Taipei, Taiwan

${ }^{4}$ Division of Nephrology, Department of Internal Medicine, Tri-Service General Hospital, National Defense Medical Center, Taipei, Taiwan

${ }^{5}$ Department of Public Health, Fu Jen Catholic University, New Taipei City, Taiwan

${ }^{6}$ School of Health Care Administration, Taipei Medical University, Taipei, Taiwan

Correction notice This article has been corrected since it first published. The provenance and peer review statement has been included.

Acknowledgements The database this study used was supported by a project that corresponding authorChiung-hsuan Chiu undertook with the Health Promotion Administration, Ministry of Health and Welfare, Taiwan, ROC (MOHW105-HPA-M-114-112101).

Collaborators $\mathrm{CH}$ Chiu is the major collaborator in this study.

Contributors Y-CC, S-FW, Y-CC and C-JW designed and conceived the study. S-FW and CC acquired and analysed the data set. Y-CC, S-FW, Y-JH, C-JW and $\mathrm{CCH}$ carried out the study and prepared the manuscript. CC and Y-CC responded to editorial and reviewers' comments. Y-CC and S-FW equally contributed to this study as first authors. All authors read and approved the final manuscript.

Funding This study was financially supported by the Health Promotion Administration, Ministry of Health and Welfare, Taiwan, ROC (MOHW103HPA-H-114-112104, MOHW104-HPA-H-114-122105).

Competing interests None declared.

Patient and public involvement Patients and/or the public were not involved in the design, or conduct, or reporting, or dissemination plans of this research.

Patient consent for publication Not required.

Ethics approval and consent to participate The Ethics Committee of Taipei Medical University approved the study protocol (approval number TMU-JIRB N201512052).

Provenance and peer review Not commissioned; externally peer reviewed.

Data availability statement Data may be obtained from a third party and are not publicly available. The data sets generated and analysed during the current study are not publicly available due the contract with Health Promotion Administration, and the authors have no special access privileges to access the data.

Open access This is an open access article distributed in accordance with the Creative Commons Attribution Non Commercial (CC BY-NC 4.0) license, which permits others to distribute, remix, adapt, build upon this work non-commercially, and license their derivative works on different terms, provided the original work is properly cited, appropriate credit is given, any changes made indicated, and the use is non-commercial. See: http://creativecommons.org/licenses/by-nc/4.0/.

ORCID iD

Chiung-hsuan Chiu http://orcid.org/0000-0002-6030-5960

\section{REFERENCES}

1 Barbour SJ, Schachter M, Er L, et al. A systematic review of ethnic differences in the rate of renal progression in CKD patients. Nephrol Dial Transplant 2010;25:2422-30.

2 Chen N, Hsu C-C, Yamagata K, et al. Challenging chronic kidney disease: experience from chronic kidney disease prevention programs in Shanghai, Japan, Taiwan and Australia. Nephrology 2010;15 Suppl 2:31-6.

3 Collins AJ, Gilbertson DT, Snyder JJ, et al. Chronic kidney disease awareness, screening and prevention: rationale for the design of a public education program. Nephrology 2010;15 Suppl 2:37-42.

4 Hay SI, Abajobir AA, Abate KH, et al. Global, regional, and national disability-adjusted life-years (DALYs) for 333 diseases and injuries and healthy life expectancy (HALE) for 195 countries and territories, 1990-2016: a systematic analysis for the global burden of disease study 2016. The Lancet 2017;390:1260-344.

5 McCullough PA, Jurkovitz CT, Pergola PE, et al. Independent components of chronic kidney disease as a cardiovascular risk state: results from the kidney early evaluation program (keep). Arch Intern Med 2007;167:1122-9. 
6 McCullough PA, Li S, Jurkovitz CT, et al. Chronic kidney disease, prevalence of premature cardiovascular disease, and relationship to short-term mortality. Am Heart J 2008;156:277-83.

7 Couser WG, Remuzzi G, Mendis S, et al. The contribution of chronic kidney disease to the global burden of major noncommunicable diseases. Kidney Int 2011;80:1258-70.

8 Mahdavi-Mazdeh M. Why do we need chronic kidney disease screening and which way to go? Iran J Kidney Dis 2010;4:275-81.

9 Obrador GT, Mahdavi-Mazdeh M, Collins AJ, et al. Establishing the global kidney disease prevention network (KDPN): a position statement from the National kidney Foundation. Am J Kidney Dis 2011;57:361-70.

10 Bayliss EA, Bhardwaja B, Ross C, et al. Multidisciplinary team care may slow the rate of decline in renal function. Clin J Am Soc Nephrol 2011;6:704-10.

11 Chen Y-R, Yang Y, Wang S-C, et al. Effectiveness of multidisciplinary care for chronic kidney disease in Taiwan: a 3-year prospective cohort study. Nephrol Dial Transplant 2013;28:671-82.

12 Hemmelgarn BR, Manns BJ, Zhang J, et al. Association between multidisciplinary care and survival for elderly patients with chronic kidney disease. J Am Soc Nephrol 2007;18:993-9.

13 Garcia-Garcia G, Martinez-Castellanos Y, Renoirte-Lopez K, et al. Multidisciplinary care for poor patients with chronic kidney disease in Mexico. Kidney Int Suppl 2013;3:178-83.

14 Hsieh H-M, Lin M-Y, Chiu Y-W, et al. Economic evaluation of a preESRD pay-for-performance programme in advanced chronic kidney disease patients. Nephrol Dial Transplant 2017;32:1184-94.

15 Bolton WK, Owen WF. Preparing the patient for renal replacement therapy. Postgrad Med 2002;111:97-108.

16 Lin M-Y, Cheng L-J, Chiu Y-W, et al. Effect of national pre-ESRD care program on expenditures and mortality in incident dialysis patients: a population-based study. PLoS One 2018;13:e0198387.

17 Shi Y, Xiong J, Chen Y, et al. The effectiveness of multidisciplinary care models for patients with chronic kidney disease: a systematic review and meta-analysis. Int Urol Nephrol 2018;50:301-12.

18 Devins GM, Mendelssohn DC, Barré PE, et al. Predialysis psychoeducational intervention and coping styles influence time to dialysis in chronic kidney disease. Am J Kidney Dis 2003;42:693-703.

19 Harris LE, Luft FC, Rudy DW, et al. Effects of multidisciplinary case management in patients with chronic renal insufficiency. Am J Med 1998:105:464-71.

20 Goldstein M, Yassa T, Dacouris N, et al. Multidisciplinary predialysis care and morbidity and mortality of patients on dialysis. Am J Kidney Dis 2004;44:706-14.

21 Khan UA, Garg AX, Parikh CR, et al. Prevention of chronic kidney disease and subsequent effect on mortality: a systematic review and meta-analysis. PLoS One 2013;8:e71784

22 Lin M, Hwang S. Epidemiology of chronic kidney disease/end-stage kidney disease - past, present, and future. Kidney and Dialysis 2007;19:1-5

23 Health Promotion Administration. Health promotion institutions of kidney disease in 2018. health promotion administration, 2020. Available: http://www.hpa.gov.tw/pages/detail.aspx?nodeid=635\& pid $=1201$

24 Wu I-W, Wang S-Y, Hsu K-H, et al. Multidisciplinary predialysis education decreases the incidence of dialysis and reduces mortality-a controlled cohort study based on the NKF/DOQI guidelines. Nephrol Dial Transplant 2009;24:3426-33.

25 Wei S-Y, Chang Y-Y, Mau L-W, et al. Chronic kidney disease care program improves quality of pre-end-stage renal disease care and reduces medical costs. Nephrology 2010;15:108-15.

26 National Health Insurance Administration. Act of payment to improve early-CKD care model under national health insurance. Bureau of national health insurance, 2020. Available: https://www.nhi.gov.tw/ Resource/webdata/26254 1 Early\%20CKD\%E8\%A8\%88\%E7\% 95\%AB.pdf

27 Miller TE. Managed care regulation: in the laboratory of the states. JAMA 1997;278:1102-9.

28 Dreiher J, Comaneshter DS, Rosenbluth Y, et al. The association between continuity of care in the community and health outcomes: a population-based study. Isr J Health Policy Res 2012;1:21.
29 Iglehart JK. No place like home - testing a new model of care delivery. N Engl J Med Overseas Ed 2008;359:1200-2.

30 Cueto-Manzano AM, Martínez-Ramírez HR, Cortés-Sanabria L. Comparison of primary health-care models in the management of chronic kidney disease. Kidney Int Supp/ 2013;3:210-4.

31 Cabana MD, Jee SH. Does continuity of care improve patient outcomes? J Fam Pract 2004;53:974-80.

32 Chen $\mathrm{C}-\mathrm{C}$, Cheng S-H. Continuity of care and changes in medication adherence among patients with newly diagnosed diabetes. Am J Manag Care 2016;22:136-42.

33 Hong J-S, Kang H-C. Continuity of ambulatory care and health outcomes in adult patients with type 2 diabetes in Korea. Health Policy 2013;109:158-65.

34 Chen C-C, Cheng S-H. Does pay-for-performance benefit patients with multiple chronic conditions? Evidence from a universal coverage health care system. Health Policy Plan 2016;31:83-90.

$35 \mathrm{Nam}$ YS, Cho KH, Kang H-C, et al. Greater continuity of care reduces hospital admissions in patients with hypertension: an analysis of nationwide health insurance data in Korea, 2011-2013. Health Policy 2016;120:604-11.

$36 \mathrm{Kao} \mathrm{Y}-\mathrm{H}$, Tseng T-S, Ng Y-Y, et al. Association between continuity of care and emergency department visits and hospitalization in senior adults with asthma-COPD overlap. Health Policy 2019;123:222-8.

37 National Health Insurance Administration. Q\&A for pay-forperformance for early-CKD patients under The National Health Insurance Bureau of National Health Insurance, 2020. Available: http://sc-dr.tw/health_form/inquire/09_04.pdf [Accessed 2020.12.18]

38 United States Renal Data System. 2014 USRDS annual data report epidemiology of kidney disease in the United States. United States renal data system, 2015. Available: https://doi.org/10.1053/j.ajkd. 2015.05.001 [Accessed 2020.12.18].

39 National Health Insurance Administration. The operationa definition of medical quality indicators. National health insurance administration, 2020. Available: http://sc-dr.tw/health form/files/ IndexDefine.pdf

40 Romano PS, Roos LL, Jollis JG. Adapting a clinical comorbidity index for use with ICD-9-CM administrative data: differing perspectives. J Clin Epidemiol 1993;46:1075-9. discussion 10811090.

41 Chang C, Chen W, Chen C, et al. Impact of chronic kidney disease on outcome of total hip replacement patients. Taiwan J Public Health 2016;35:53-65.

42 Chu Y, SC W. A review of Claims-based comorbidity measures. Taiwan J Public Health 2010;29:8-21.

43 Kidney Disease Improvement Global Outcomes. Clinical practice guideline for the evaluation and management of chronic kidney disease. J Int Soc nephrology 2020;3:1-163.

44 Boult C, Reider L, Leff B, et al. The effect of guided care teams on the use of health services: results from a cluster-randomized controlled trial. Arch Intern Med 2011;171:460-6.

45 Weber C, Beaulieu M, Djurdjev O, et al. Towards rational approaches of health care utilization in complex patients: an exploratory randomized trial comparing a novel combined clinic to multiple specialty clinics in patients with renal disease-cardiovascular disease-diabetes. Nephrol Dial Transplant 2012;27 Suppl 3:iii104-10.

46 Levine S, Steinman BA, Attaway K, et al. Home care program for patients at high risk of hospitalization. Am J Manag Care 2012;18:e269-76.

47 Lin T-Y, Chen C-Y, Huang YT, et al. The effectiveness of a pay for performance program on diabetes care in Taiwan: a nationwide population-based longitudinal study. Health Policy 2016;120:1313-21.

48 Vassalotti JA, Centor R, Turner BJ, et al. Practical approach to detection and management of chronic kidney disease for the primary care clinician. Am J Med 2016;129:153-62.

49 Hopman P, de Bruin SR, Forjaz MJ, et al. Effectiveness of comprehensive care programs for patients with multiple chronic conditions or frailty: a systematic literature review. Health Policy 2016;120:818-32.

50 World Health Organization. Integrated care models: an overview, 2020. Available: http://www.euro.who.int/_data/assets/pdf_file/ 0005/322475/Integrated-care-models-overview.pdf 